\title{
Dietary Treatment of Eosinophilic Esophagitis in Children
}

\author{
Amir F. Kagalwalla \\ Department of Pediatrics - Gastroenterology, Hepatology and Nutrition, Northwestern University Feinberg \\ School of Medicine, Ann and Robert H. Lurie Children's Hospital of Chicago, and John H. Stroger Hospital of \\ Cook County, Chicago, III., USA
}

\section{Key Words}

Six-food elimination diet · Elemental diet · Patch testing

\begin{abstract}
Eosinophilic esophagitis (EoE) is a chronic inflammatory disorder of the esophagus that, in a genetically susceptible host, is triggered by a food antigen. Emerging evidence supports impaired epithelia barrier function as the key initial event in the development of EoE and other allergic diseases. Symptom resolution, histologic remission, and prevention of both disease and treatment-related complications are the goals of treatment. Successful dietary treatments include elemental and elimination diets, both empiric and allergy test directed. These treatments are dietary approaches to inducing clinical and histologic remission. Dietary therapy with an exclusive elemental diet offers the best response with a remission rate of more than $96 \%$. Empiric elimination diets and allergy-directed diets offer similar response with remission induced in 3 of 4 subjects (75\%). Cow's milk, wheat, egg and soy are the four common food antigens most likely to induce esophageal inflammation.
\end{abstract}

\section{Introduction}

Eosinophilic esophagitis (EoE) is an antigen/immunemediated chronic inflammatory disorder that, in a genetically susceptible individual, is triggered by food antigens.
EoE in children was first described in 1995 in a case study demonstrating reversal of clinical symptoms and esophageal eosinophilic inflammation with replacement of all food antigens with an exclusive amino acid-based elemental diet [1]. Specific food antigens including cow's milk, soy, wheat, egg and peanuts were shown as potential proteins that induced the esophageal inflammation. These seminal observations from that study have become the basis of the different dietary approaches currently offered to treat EoE.

As is true for the treatment of most other chronic disorders, the goals of treatment in EoE include: (1) resolution of clinical symptoms, (2) maintenance of remission, (3) prevention of complications such as fibrosis and strictures by maintaining histologic remission, (4) prevention of iatrogenic treatment-related adverse reactions such as nutritional deficiencies in dietary treatment, and (5) maintenance of quality of life.

The dietary approach is based on the hypothesis that food antigens trigger eosinophilic inflammation, and both clinical and histologic remission can be induced by identifying and excluding the causative food antigens. Eliminating causative food antigens targets the cause, thus eliminating and continuously avoiding the food antigen and thereby inducing long-term remission. There are no prospective studies assessing the efficacy of the different dietary approaches in children. The current recommendation for treatment of EoE with diet are based on a number of retrospective and observational studies [2-

\section{KARGER}

E-Mail karger@karger.com

www.karger.com/ddi
(C) 2014 S. Karger AG, Basel

0257-2753/14/0322-0114\$39.50/0
Assoc. Prof. Amir F. Kagalwalla, MBBS

Ann and Robert H. Lurie Children's Hospital of Chicago

225 E. Chicago Ave., Box 57

Chicago, IL 60611 (USA)

E-Mail akagalwalla@luriechildrens.org 
Table 1. Dietary introduction approach to food reintroduction in EoE

\begin{tabular}{|c|c|c|c|}
\hline \multicolumn{3}{|l|}{ Start (least allergenic) } & \multirow{2}{*}{$\begin{array}{l}\text { End (most allergenic) } \\
\text { D }\end{array}$} \\
\hline A & $\mathrm{B}$ & $\mathrm{C}$ & \\
\hline $\begin{array}{l}\text { Vegetables (nonlegume) } \\
\text { Carrots, squash (all types), } \\
\text { sweet potatoes, white potatoes, } \\
\text { string beans, broccoli, lettuce, } \\
\text { beets, asparagus, cauliflower, } \\
\text { brussel sprouts } \\
\text { Fruit (noncitrus, nontropical) } \\
\text { Apples, pears, peaches, plums, } \\
\text { apricots, nectarines, grapes, raisins } \\
\text { Vegetables } \\
\text { Tomatoes, celery, cucumbers, } \\
\text { onions, garlic, any other vegetables }\end{array}$ & $\begin{array}{l}\text { Citrus fruits } \\
\text { Oranges, grapefruits, lemons, limes } \\
\text { Tropical fruits } \\
\text { Bananas, kiwis, pineapples, mangos, } \\
\text { papayas, guavas, avocados } \\
\text { Melons } \\
\text { Honeydew, cantaloupe, watermelon } \\
\text { Berries } \\
\text { Strawberries, blueberries, raspberries, } \\
\text { cherries, cranberries } \\
\text { Grains } \\
\text { Rice, millet, quinoa }\end{array}$ & $\begin{array}{l}\text { Legumes } \\
\text { Lima beans, chickpeas, } \\
\text { white/black/red beans } \\
\text { Grains } \\
\text { Oats, barley, rye, } \\
\text { other grains } \text { Meat }^{1} \\
\text { Lamb, chicken, turkey, } \\
\text { pork }\end{array}$ & $\begin{array}{l}\text { Fish/shellfish } \\
\text { Corn } \\
\text { Peas } \\
\text { Peanuts } \\
\text { Wheat } \\
\text { Beef } \\
\text { Soy } \\
\text { Eggs } \\
\text { Milk }\end{array}$ \\
\hline
\end{tabular}

Modified with permission from Markowitz et al. [4]. ${ }^{1}$ Progress from well-cooked to rarer.

7]. The available dietary approaches include: (1) an elemental diet with an amino acid-based complete liquid formulation $[1,2,4],(2)$ a directed elimination diet based on the results of allergy testing [5], and (3) an empiric or nondirected elimination diet where a number of common food antigens are initially and temporarily excluded from the diet [3]. The type of treatment selected should be tailored to the needs of the patient. The selection will depend on the age of the child, the presence of comorbid malnutrition and feeding aversion, and the comfort and acceptance of the elimination diet by the family. Outcomes of all the different dietary approaches are summarized in figure 1.

\section{Elemental Diet}

In a cohort of 10 children with gastroesophageal reflux disease-like symptoms that had been resistant to prior acid suppression, a crystalline amino-acid based (exclusive) elemental formula in lieu of a regular diet induced clinical and histologic remission. Subsequent controlled reintroduction of solid foods resulted in recurrence of gastrointestinal symptoms specific to individual foods. A clear link between food allergy and esophageal injury was thus established in these patients [1]. Since this seminal publication by Kelly et al. [1], two series of 172 and 25 cases reported a remission rate of 96 and 88\%, respectively, in children treated with an elemental diet without any reported complications [2-4]. The likelihood of

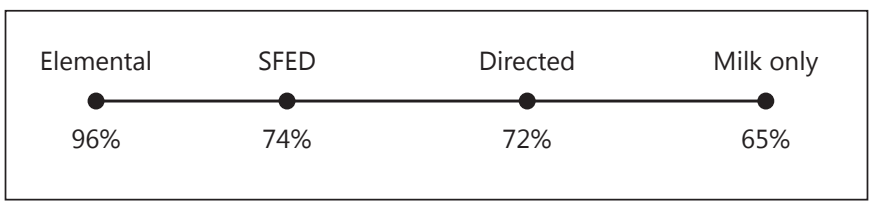

Fig. 1. Spectrum of different dietary treatments by response.

achieving mucosal healing is higher with this modality than other dietary or pharmacologic treatment with corticosteroids. The added advantage is the much lower residual eosinophil counts. The disadvantage of this approach is compliance secondary to the poor taste. This is also the reason why many of these children require either nasogastric or gastrostomy tubes to deliver adequate nutrients. Limiting a child to an exclusive elemental diet may also restrict the child's participation in social activities, since many childhood activities involve food, which can lead to impaired quality of life. The elemental formulas are expensive and this can potentially place significant financial and social burden on the families. There may also be additional costs related to tubes, pumps, bags, and other supplies.

Following demonstration of histologic remission 4-6 weeks after the exclusive elemental diet, food reintroduction is initiated beginning with the least allergenic foods from vegetable or fruit groups, then single foods are introduced every 5-7 days, and followed by single foods from the most allergic food group which includes cow's 
milk, soy, wheat, egg, beef, and corn. The reintroductions are outlined by Markowitz et al. [4] as shown in table 1 . Following successful reintroduction of all foods in one food group, endoscopic esophageal biopsies are performed to demonstrate continuing remission before introducing the next single food from the next food group. In this process, if symptoms are elicited with an ingested food, then the symptom-inducing food is excluded from the diet and the next food in that group is introduced once the symptoms have resolved.

\section{Directed Elimination Diets}

Elimination diets based only on the results of RAST and/or a skin prick test (SPT) have failed to demonstrate clinical and histologic remission [7-9]. In a prospective study in adults treated with empiric elimination diet who also underwent SPT, the predictive value of SPT for causal foods was only $13 \%$ in subjects [6]. RAST testing and SPT alone or together fail to correctly identify foods causing esophageal inflammation in most patients. However, an elimination diet in children based on the combined results of SPT and atopic patch testing (APT) resulted in clinical and histologic remission in 72\% [5]. Patients in this series were tested on a total of 23 foods in five food groups that included meats (chicken, turkey, beef, and pork), vegetables (peas, string beans, squash, sweet potatoes, potatoes, and carrots), fruits (apples, pears, and peaches), grains (wheat, rice, rye, oats, barley, and corn) and a final group which included cow's milk, soy, eggs, and peanuts. The foods most frequently identified in patients who underwent a combination of APT and SPT were milk, soy, wheat, chicken, and beef. Other investigators utilizing patch testing in children have been unable to reproduce the high response rates elicited by Spergel et al. $[19,20]$. Possible reasons include lack of validation between EoE and control population, and lack of standardization of whether fresh or preserved food extracts are used for testing. For all of these reasons, patch testing remains primarily a research tool [10].

\section{Empiric Elimination Diets}

The empiric or nondirected elimination diet does not require allergy testing to determine foods for elimination from the diet, which is the major advantage of this dietary approach over the directed elimination diet. In a study of children treated with a six-food elimination diet
(SFED; i.e. excluding cow's milk protein, wheat, egg, soy, peanut/tree nuts, and fish/shellfish [3]), 26 of 35 children (74\%) experienced significant clinical and histologic improvement (esophageal eosinophil count $\leq 10 /$ high-power field). There was complete mucosal healing with 0-1 eosinophils/high-power field documented in 7 of these 26 children (27\%). The histologic response to the elimination diet is shown in figure 2 . Two additional studies have recently validated the results of SFED with the histologic response ranging from 50 to $81 \%[11,12]$. This treatment approach has also been validated in adults with a recent prospective study demonstrating histologic improvement in $72 \%$ of patients treated with SFED [6]. In a follow-up study of children achieving histologic remission on SFED, milk was the single most common food and was responsible for triggering eosinophilic esophageal inflammation in $74 \%$ of subjects, followed by wheat in $26 \%$, egg in $17 \%$, and soy in $10 \%$ [13]. Two additional studies have validated the findings of the initial publication identifying milk, wheat, egg, and soy as the four foods most likely to trigger inflammation in EoE $[11,12]$.

In the interest of simplification, dietary therapy can be broadly divided into three stages. The first is the remission stage in which multiple foods are concurrently eliminated, as described above, and it is applicable for both elemental and elimination diets. The second stage is the reintroduction stage which is characterized by reintroduction of one of the excluded foods sequentially every 6-8 weeks followed by endoscopy and biopsies in the responders. When there is recurrence of inflammation, the incriminating trigger food is excluded from the diet and the next food is added until all the excluded foods are reintroduced. Ultimately the reintroduction process identifies one or rarely two foods as the cause of esophageal inflammation. The third is the maintenance stage, during which the incriminating food(s) identified during the reintroduction stage is (are) the only food(s) excluded long-term. There are currently no pediatric studies demonstrating the efficacy of long-term continuous elimination of incriminating food antigen(s) maintaining disease remission in children.

The primary advantage of an elimination diet over an exclusive elemental diet is that it allows the intake of a variety of table foods including meats, grains, fruits, vegetables, and legumes compared to a single nutrient source taken orally or via a tube. The major limitation of an empiric elimination diet is the difficulties associated with simultaneously eliminating multiple foods even if for a lim- 
Fig. 2. Pre- and posttreatment peak eosinophil counts after SFED $(\mathrm{n}=35)$. Reprinted from original article by Kagalwalla et al. [3].

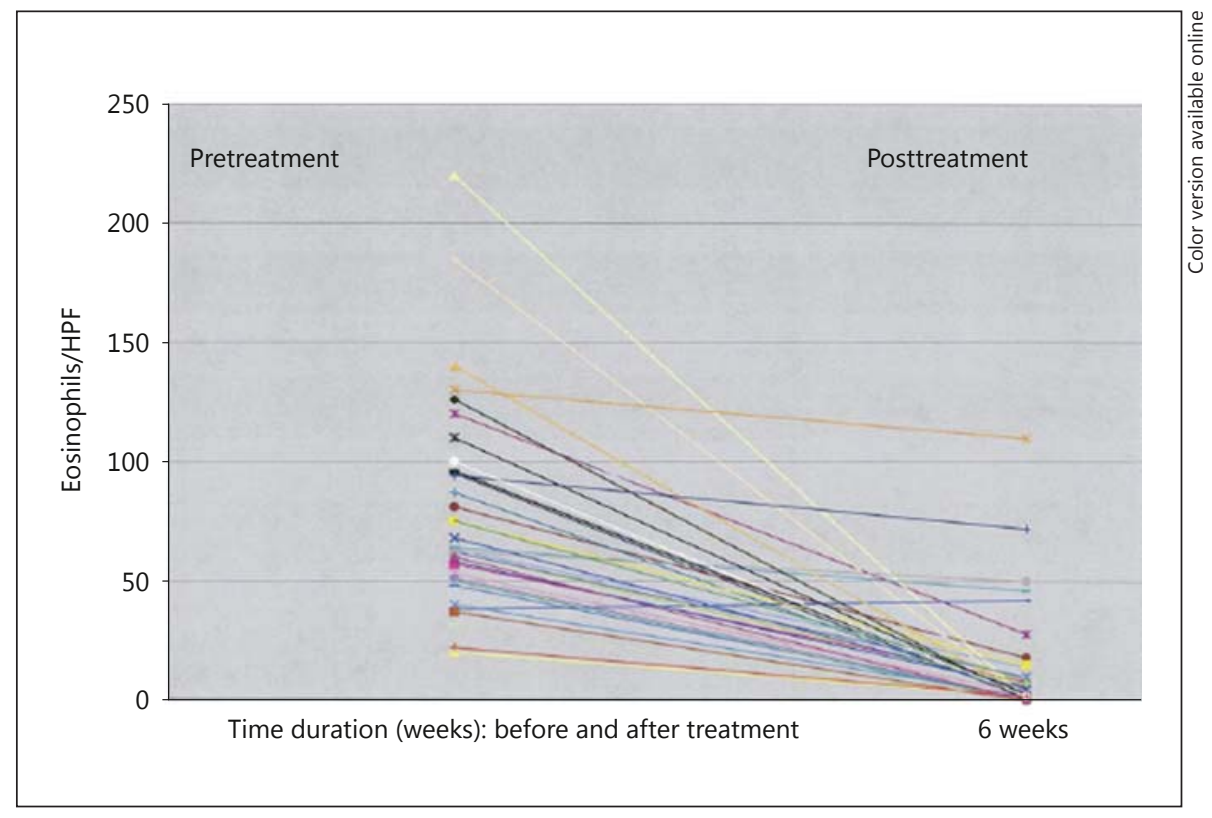

ited time. There is poor correlation between symptoms and disease activity, and in the absence of noninvasive tests, multiple endoscopies are required to identify recurrence of inflammation, which occurs when the incriminating foods are reintroduced back in the diet of the responders.

\section{Nutritional Assessment}

Nutritional assessment of children with EoE prior to initiating an elimination diet improves compliance of the prescribed nutritional therapy. It involves obtaining a detailed nutritional history, including descriptions of the food and supplements being consumed (including brand names of foods), preparation methods, and eating environment. Younger children with vomiting, feeding aversion, and multiple IgE-mediated food allergies may present with malnutrition. The initial assessment may also identify preexisting nutritional deficiencies which can be addressed concurrently when prescribing an elimination diet. Children who are on elimination diets for a prolonged period will need to have their nutritional intake monitored. In addition to anthropometric measurements including weight, height, and BMI, some children, especially those who have a large number of foods excluded, will require biochemical tests including a complete blood count, prealbumin, iron, calcium, and vitamin D levels to monitor for deficiencies $[14,15]$.

Dietary Treatment of EoE in Children

\section{Food Substitutions and Cross-Contamination}

The deleterious consequences of eliminating major foods such as milk, soy, wheat or egg from the diet of a growing child are addressed by involvement of a dietitian with understanding and expertise in food substitution. Adequate food substitution of the excluded foods ensures a nutritionally complete diet. This requires knowledge and understanding of the nutrient deficiencies caused by elimination of specific food as well the appropriate substitution for that food as shown in table 2 .

Another important aspect of eliminating foods from the diet involves understanding and preventing food cross-contamination. Cross-contamination can transform a naturally occurring antigen-free food into an antigen-containing food. Cross-contamination can occur during processing, preparing, cooking, or serving food. Many processed foods, including fast foods, may be crosscontaminated with one or more foods such as milk, soy, wheat, or nuts. Cross-contamination can also occur during the process of food preparation at home and can be avoided by simple measures such as using different utensils and strict hand washing between cooking different foods.

Reading food labels is a must to ensure that those products are not allowed in the diet. Food labels should be reviewed every time because manufacturing or processing may have changed, and a food that was formerly antigen-free may contain the excluded antigen. 
Table 2. Potential nutritional deficiencies

\begin{tabular}{|c|c|c|}
\hline Food & Nutrients & $\begin{array}{l}\text { Alternative food } \\
\text { sources }\end{array}$ \\
\hline Milk & $\begin{array}{l}\text { protein, calcium, vitamin } \mathrm{D} \text {, } \\
\text { vitamin } \mathrm{A}, \mathrm{B}_{12} \text {, riboflavin, } \\
\text { pantothenic acid, potassium }\end{array}$ & $\begin{array}{l}\text { meats, legumes, } \\
\text { whole grains, nuts, } \\
\text { fortified foods (with } \\
\text { B vitamins, calcium, } \\
\text { vitamin D) }\end{array}$ \\
\hline Egg & $\begin{array}{l}\text { protein, vitamin } B_{12}, \\
\text { pantothenic acid, biotin, } \\
\text { selenium }\end{array}$ & $\begin{array}{l}\text { meat, chicken, } \\
\text { legumes, whole } \\
\text { grains }\end{array}$ \\
\hline Soy & $\begin{array}{l}\text { protein, iron, zinc, magnesium, } \\
\text { thiamin, riboflavin, pyridoxine, } \\
\text { folate }\end{array}$ & meats, allowed grains \\
\hline Wheat & $\begin{array}{l}\text { iron, thiamin, riboflavin, } \\
\text { niacin, folic acid }\end{array}$ & $\begin{array}{l}\text { alternative grains } \\
\text { that are fortified }\end{array}$ \\
\hline $\begin{array}{l}\text { Peanut/ } \\
\text { tree nut }\end{array}$ & $\begin{array}{l}\text { vitamin } \mathrm{E} \text {, niacin, magnesium, } \\
\text { manganese, chromium, folic } \\
\text { acid, } \mathrm{B}_{6} \text {, copper, zinc, selenium, } \\
\text { phosphorus, potassium }\end{array}$ & $\begin{array}{l}\text { legumes, whole } \\
\text { grains, vegetable oils }\end{array}$ \\
\hline $\begin{array}{l}\text { Fish/ } \\
\text { shellfish }\end{array}$ & $\begin{array}{l}\text { vitamin } \mathrm{E}, \mathrm{B}_{6} \text {, niacin, } \\
\text { phosphorus, selenium, } \\
\text { omega-3 fatty acids }\end{array}$ & $\begin{array}{l}\text { whole grains, meats, } \\
\text { soybeans, flaxseed, } \\
\text { nuts, oils }\end{array}$ \\
\hline
\end{tabular}

\section{Complications}

Exclusion of important food elements from a growing child's diet can have disastrous consequences including impaired growth, rickets, and vitamin deficiencies [16-18]. Kwashiorkor from protein-calorie malnutrition has been reported in children with only milk protein exclusion from the diet of toddlers suspected of milk protein allergy [18]. Frequently, it is not only the exclusion of one specific food that results in nutritional deficiency, but also the concurrent exclusion of processed foods that may contain that particular food antigen.

Elimination diets with the emphasis on excluding milk, wheat, soy, and nuts among other foods can also be challenging for children on a vegan diet. Participation of a registered dietitian ensures a calorically adequate diet for growth, provides education on appropriate food substitutions, prevents contamination with excluded food antigens, and is an ongoing resource for families as they learn to adapt to the diet modification.

\section{Conclusion}

Dietary treatment is a logical approach to treating EoE. Identification and exclusion of specific food triggers leads to resolution of symptoms and esophageal mucosal healing. Implementation of the various dietary treatments can often be challenging and may be difficult to implement. An elemental diet with complete elimination of all intact food antigens offers the best outcome results as well as the most complete healing; however, the major drawback is excluding all solid foods and the long food reintroduction process which is often frustrating.

The directed and empiric elimination diets that require the elimination of a limited number of foods is more readily acceptable compared to the complete elimination of all intact food proteins from the diet as required by the elemental diet. Although the responses to directed and empiric elimination diets are similar, the directed elimination diet requires the additional step of subjecting the patients to allergy testing without providing added advantage. Furthermore, allergy testing has limitations. SPT alone is ineffective in identifying the trigger foods and APT is not validated, not universally available, and hard to replicate.

Elimination diets are an acceptable modality to treat children with EoE, despite the limitations of requiring multiple endoscopies. The future availability of a minimally or noninvasive test would alleviate the current difficulties with administering dietary management. One size does not fit all when considering different dietary therapies and it is important to remember that success with the dietary approach is primarily contingent on tailoring the specific treatment to the needs of individual patients.

\section{Acknowledgements}

The author acknowledges Ms. Sally Schwartz for her invaluable insights on dietary therapy and Ms. Katie Amsden and Ms. Kristin Johnson for their assistance in writing this article.

\section{Disclosure Statement}

The author serves on the speaker's bureau of Nutricia.

References

1 Kelly KJ, Lazenby AJ, Rowe PC, Yardley JH, Perman JA, Sampson HA: Eosinophilic esophagitis attributed to gastroesophageal reflux: improvement with amino acid-based formula. Gastroenterology 1995;109:15031512. 
-2 Liacouras CA, Spergel JM, Ruchelli E, Verma R, Mascarenhas M, Semeao E, Flick J, Kelly J, Brown-Whitehorn T, Mamula P, Markowitz JE: Eosinophilic esophagitis: a 10-year experience in 381 children. Clin Gastroenterol Hep 2005;3:1198-1206.

3 Kagalwalla AF, Sentongo TA, Ritz S, Hess T, Nelson SP, Emerick KM, Melin-Aldana H, Li BU: Effect of six-food elimination diet on clinical and histologic outcomes in eosinophilic esophagitis. Clin Gastroenterol Hep 2006;4:1097-1102.

4 Markowitz JE, Spergel JM, Ruchelli E, Liacouras CA: Elemental diet is an effective treatment for eosinophilic esophagitis in children and adolescents. Am J Gastroenterol 2003;98: 777-782.

5 Spergel JM, Andrews T, Brown-Whitehorn TF, Beausoleil JL, Liacouras CA: Treatment of eosinophilic esophagitis with specific food elimination diet directed by a combination of skin prick and patch tests. Ann Allergy Asthma Immunol 2005;95:336-343.

-6 Gonsalves N, Yang GY, Doerfler B, Ritz S, Ditto AM, Hirano I: Elimination diet effectively treats eosinophilic esophagitis in adults; food reintroduction identifies causative factors. Gastroenterology 2012;142:1451-1459.

7 Spergel JM, Shuker M: Nutritional management of eosinophilic esophagitis. Gastrointest Endoscopy Clin N Am 2008;18:179-194.
8 Teitelbaum JE, Fox VL, Twarog FJ, Nurko S, Antonioli D, Gleich G, Badizadegan K, Furuta GT: Eosinophilic esophagitis in children: immunopathological analysis and response to fluticasone propionate. Gastroenterology 2002;122:1216-1225.

-9 Noel RJ, Putnam PE, Collins MH, Assa'ad AH, Guajardo JR, Jameson SC, Rothenberg ME: Clinical and immunopathologic effects of swallowed fluticasone for eosinophilic esophagitis. Clin Gastroenterol Hep 2004;2: 568-575.

10 Assa'ad A: Detection of causative foods by skin prick and atopy patch tests in patients with eosinophilic esophagitis: things are not what they seem. Ann Allergy Asthma Immunol 2005;95:309-311.

-11 Spergel JM, Brown-Whitehorn TF, Cianferoni A, Shuker M, Wang ML, Verma R, Liacouras CA: Identification of causative foods in children with eosinophilic esophagitis treated with an elimination diet. J Allergy Clin Immunol 2012;130:461-467.

12 Henderson CJ, Abonia JP, King EC, Putnam PE, Collins MH, Franciosi JP, Rothenberg ME: Comparative dietary therapy effectiveness in remission of pediatric eosinophilic esophagitis. J Allergy Clin Immunol 2012; 129:1570-1578.

13 Kagalwalla AF, Shah A, Li BUK, Sentongo TA, Ritz S, Manuel-Rubio M, Jacques K, Wang D, Melin-Aldana H, Nelson SP: Identification of specific foods responsible for inflammation in children with eosinophilic esophagitis successfully treated with empiric elimination diet. J Pediatr Gastroenterol Nutr 2011;53:145-149.
14 Salman S, Christie L, Burks W, Mccabe-Sellers B: Dietary intakes of children with food allergies: comparison of the food guide pyramid and the recommended dietary allowances 10th ed. J Allergy Clin Immun 2002; 109:S214.

15 Mofidi S: Nutritional management of pediatric food hypersensitivity. Pediatrics 2003;111: 1645-1653.

16 Carvalho NF, Kenney RD, Carrington PH, Hall DE: Severe nutritional deficiencies in toddlers resulting from health food milk alternatives. Pediatrics 2001;107:E46.

17 Noimark L, Cox HE: Nutritional problems related to food allergy in childhood. Pediatr Allergy Immunol 2008;19:188-195.

18 Liu T, Howard RM, Mancini AJ, Weston WL, Paller AS, Drolet BA, Esterly NB, Levy ML, Schachner L, Frieden IJ: Kwashiorkor in the United States: fad diets, perceived and true milk allergy, and nutritional ignorance. Arch Dermatol 2001;137:630-636.

19 Rizo Pascual JM, De La Hoz Caballer B, Redondo Verge C, et al: Allergy assessment in children with eosinophilic esophagitis. J Investig Allergol Clin Immunol 2011;21:59-65.

20 Paquet B, Bégin P, Paradis L, et al: Variable yield of allergy patch testing in children with eosinophilic esophagitis. J Allergy Clin Immunol 2013;131:613. 